\title{
Prognostic Role of Apelin Receptor Expression in Hepatocellular Carcinoma Treated With Curative Surgical Resection
}

\author{
TAEBUM LEE ${ }^{1 *}$, CHEOL- KEUN PARK ${ }^{1,2}$ and SANG YUN HA ${ }^{1}$ \\ ${ }^{1}$ Department of Pathology and Translational Genomics, Samsung Medical Center, \\ Sungkyunkwan University School of Medicine, Seoul, Republic of Korea; \\ ${ }^{2}$ Anatomic Pathology Reference Lab, Seegene Medical Foundation, Seoul, Republic of Korea
}

\begin{abstract}
Background/Aim: apelin and apelin receptor (APJR) are involved in the regulation of angiogenesis, and their high expression is related to poor outcomes in several cancer types. Recently, several positive results on APJR antagonists in cancer treatment have been reported at the preclinical level. The aim of this study was to evaluate the prognostic effect of APJR expression on hepatocellular carcinoma (HCC) survival. Materials and Methods: We evaluated APJR expression in 288 curatively resected HCCs using immunohistochemistry and investigated the correlation with clinicopathological features. Results: High APJR expression was significantly associated with the presence of microvascular invasion $(p<0.001)$, intrahepatic metastasis $(p=0.004)$, and early recurrence $(p=0.029)$. The highexpression group showed shorter recurrence-free survival $(p<0.001)$ and overall survival $(p=0.001)$ than the lowexpression group. In multivariate analysis, high APJR expression was an independent predictor of shorter recurrence-free survival (Hazard Ratio 1.49; 95\% confidence interval 1.08-2.05, $p=0.016)$. Conclusion: We described-high APJR expression and its prognostic effect in HCC. Emerging target agents may be applicable in patients with HCC and high APJR expression.
\end{abstract}

\footnotetext{
* Present address: Department of Pathology, Chonnam National University Medical School, Hwasun Hospital, Hwasun-gun, Jeollanam-do, Republic of Korea

Correspondence to: Sang Yun Ha, MD, Ph.D., Department of Pathology and Translational Genomics, Samsung Medical Center, Sungkyunkwan University School of Medicine, 81 Irwon-ro, Gangnam-gu, Seoul 06351, Republic of Korea. Tel: +82 234106398, Fax: +82 234100025, e-mail: sangyun.ha@skku.edu
}

Key Words: Hepatocellular carcinoma, prognostic factor, apelin; apelin receptor, APJR.
Hepatocellular carcinoma (HCC) is the most common primary liver malignancy, the sixth most common cancer, and the fourth leading cause of cancer death worldwide (1). Approximately 800,000 patients are newly diagnosed and die each year globally. Although hepatic resection is the treatment of choice in HCC, it is not curative for the most patients due to the high recurrence rate of up to $70 \%$ (2). Recurrence is the main cause of death. Thus, prediction of recurrence is exceedingly important and prevention with appropriate therapy will improve patient outcome (3). Applications of target therapy are still limited despite many clinical trials. The multi-targeted kinase inhibitors sorafenib, regorafenib, and lenvatinib are approved systemic treatments in advanced HCC (4-6). Identification of new therapeutic targets and reliable biomarkers is needed to ensure more effective clinical treatment after curative resection (7).

Apelin, a ubiquitous peptide, is involved in the regulation of cardiovascular control, homeostasis, and angiogenesis (812). The significance of apelin and apelin receptor (APJR) has been studied in many tumors, including non-small cell lung cancer, colon cancer, and brain tumors (13-15). Relatively consistent results show that a high apelin level is related to vascular proliferation and poor outcome. Recently, apelin was highlighted as a promising target in the treatment of metabolic disease $(16,17)$. Several positive results using APJR antagonists in cancer treatment have been reported at the preclinical level $(14,15)$. Recently, Muto et al. reported an increased APJR expression in arterial smooth muscle cells in HCC and apelin mRNA expression in HCC. They also showed inhibition of tumor growth with APJR antagonist (18). However, APJR expression and its relation to clinical features and outcomes in HCC has not been fully elucidated.

In this study, we investigated APJR expression by immunohistochemistry (IHC) in 288 curatively resected HCC samples and analyzed the prognostic effect of APJR expression in patients with HCC and a median 119-month follow-up period. 


\section{Materials and Methods}

Patients. Initially, 291 surgically resected HCC cases were collected from the surgical pathology database at Samsung Medical Center (Seoul, Korea) between 2000 and 2006. Three cases with no residual tissue were excluded, and finally 288 cases were included in this study. All hematoxylin and eosin-stained slides were reviewed by two pathologists (CKP and $\mathrm{SYH}$ ). Clinical and laboratory data including age, sex, date of surgery, serum albumin level and alpha-feto protein (AFP) level, presence of viral hepatitis, recurrence-free survival (RFS), overall survival (OS), and followup were extracted from electronic medical records. The institutional review board of Samsung Medical Center approved this study and waived informed consent.

Curative resection was defined as complete resection of all tumor nodules without microscopic involvement of resection margins and no detected residual tumor on computed tomography (CT) scans at 1 month after surgery. Histopathologic features of HCCs, including tumor differentiation, microvascular invasion, major portal vein invasion, intrahepatic metastasis, multicentric occurrence, and nontumor liver pathology, were reviewed by two liver pathologists (SYH and CKP). Tumor differentiation was determined according to the criteria of Edmondson and Steiner (19). Intrahepatic metastasis and multicentric occurrence were distinguished according to the criteria of the Liver Cancer Study Group of Japan (20). Patients were staged according to the American Joint Committee on Cancer (AJCC) staging system (21) and Barcelona Clinic Liver Cancer (BCLC) staging classification (22).

During the follow-up period, patients underwent CT with serum AFP measurement every 2 or 3 months postoperatively. Patients with suspicious imaging findings and/or continuously elevated AFP levels were further evaluated with positron emission tomography (PET)-CT and/or magnetic resonance imaging (MRI). The median follow-up period was 119.8 months (range=14.0-151.4). Recurrence was generally diagnosed using radiologic examinations without histologic confirmation. Intrahepatic HCC recurrence within the first two years after curative resection is mainly due to intrahepatic metastasis, whereas late recurrence usually results from multicentric disease (23). Using 2 years as a cut-off, intrahepatic tumor recurrence was classified as either early or late (24).

Tissue microarray construction. Representative tumor areas free from necrosis or hemorrhage were marked in formalin-fixed paraffin-embedded blocks. Two tissue cores of $2.0 \mathrm{~mm}$ in diameter were obtained from donor blocks and arranged in recipient paraffin blocks. Two cores of normal liver tissue from 12 patients with metastatic colonic carcinoma to the liver were included in each array block. Each tissue microarray (TMA) block contained up to 60 tissue cores.

Immunohistochemical staining and evaluation. IHC was performed in 4- $\mu \mathrm{m}$-thick tissue sections from TMA blocks, using a Bondmax automated immunostainer (Leica Biosystems, Melbourne, Australia) and a Bond ${ }^{\mathrm{TM}}$ Polymer refine detection system, DS9800 (Vision Biosystems, Melbourne, Australia). The primary antibody was a rabbit polyclonal antibody against APJ Receptor antibody cytoplasmic domain (ab140508, 1:50, Abcam, Cambridge, MA, USA). Briefly, antigen retrieval was performed at $97^{\circ} \mathrm{C}$ for $20 \mathrm{~min}$ in ER2 buffer (Leica Biosystems, Melbourne, Australia). After blocking endogenous peroxidase activity with $3 \%$ hydrogen peroxide for $5 \mathrm{~min}$, primary antibody incubation was performed for $15 \mathrm{~min}$ at room temperature, and antigen-antibody chromogenic reactions were detected for $10 \mathrm{~min}$.

Brain tissue was used as positive control according to manufacturer's recommendations, and cytoplasmic staining of tumor cells was interpreted as positive. APJR staining was analyzed by a semiquantitative method using $\mathrm{H}$-score on a continuous scale of 0 to 300 by considering both percentage of stained cells and 4 intensity categories: 0 for negative, $1+$ for weak, 2+ for moderate, and $3+$ for strong positive (Figure 1). The IHC slides were independently interpreted by two pathologists (TL and SYH). In cases of disagreement, the final interpretation was determined by consensus using a multi-head microscope.

Statistical analysis. Calculated H-score was analyzed using X-tile statistical software program to determine the optimal cut-off point with the most significant prognostic effect in terms of RFS (25). Correlations between clinicopathologic data and APJR expression were analyzed by chi-square test or Fisher's exact test. Survival curves were plotted according to Kaplan-Meier analysis, and Cox proportional hazard model was used to predict RFS. Statistical analyses were performed using $\mathrm{R}$ and SPSS statistical package (IBM, NY, USA) and $p$-value $<0.05$ (two sided) was considered statistically significant.

\section{Results}

Clinicopathological features of the HCC patients. The clinicopathologic features are summarized in Table I. Among the 288 HCC cases, $237(82.3 \%)$ patients were male and 51 $(17.7 \%)$ were female, with ages ranging from 17 to 76 years old $($ median $=53)$. In preoperative laboratory tests, 30 $(10.4 \%)$ patients were hypoalbuminemic $(\leq 3.5 \mathrm{~g} / \mathrm{dl})$ and 103 $(37.1 \%)$ patients showed increased AFP level (>200 ng/ml). Forty-nine $(17.0 \%)$ patients had non-viral associated HCC, and the other cases were viral associated. A total of 209 $(72.6 \%)$ patients had hepatitis B virus (HBV), $26(9.0 \%)$ patients had hepatitis $\mathrm{C}$ virus (HCV), and 4 (1.4\%) patients had both HBV and HCV.

By histological examination, the majority of cases (233; $80.9 \%$ ) were Edmonson grade II, which was followed by grade I $(31 ; 10.8 \%)$ and grade III $(24 ; 8.3 \%)$. One-hundred fifty-six $(54.2 \%)$ cases showed peritumoral microvascular invasion, and $12(4.2 \%)$ cases had major portal vein invasion. Sixty-six $(22.9 \%)$ cases had intrahepatic metastasis, while $19(6.6 \%)$ were multicentric. In the background liver (at least $2 \mathrm{~cm}$ away from the tumor), 145 (50.3\%) cases showed cirrhosis.

One-hundred forty-two patients recurred within 2 years after surgery (early recurrence). Of the remaining 146 patients, 50 patients recurred over 2 years after surgery (late recurrence).

APJR expression and recurrence free survival. The median H-score value of APJR IHC was 115 (range=0-260) and the mean was 116.66 (standard deviation 56.58). Using X-tile 


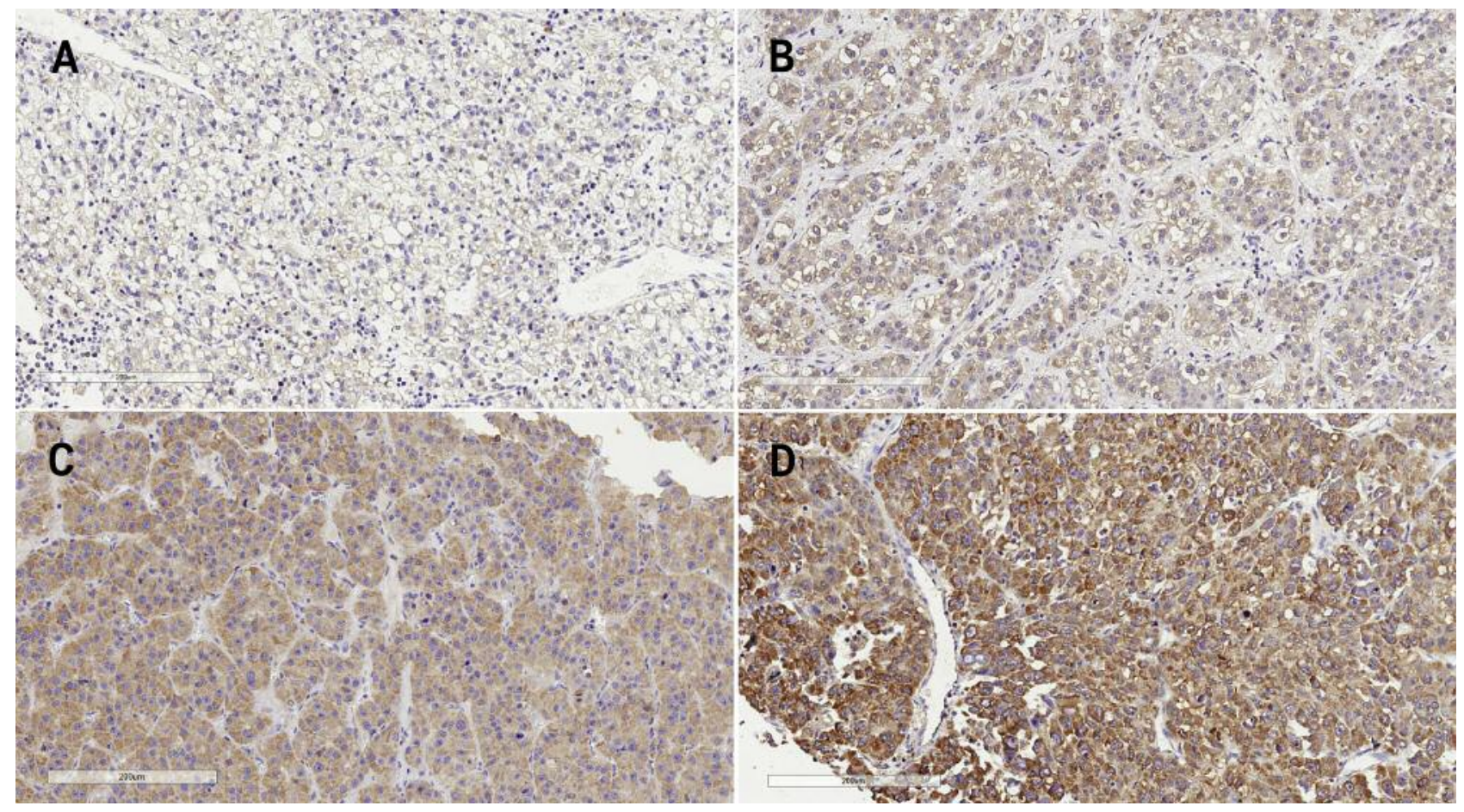

Figure 1. Representative images of apelin receptor immunohistochemistry according to intensity score: Score O (A), Score 1 (B), Score 2 (C), Score $3(D)$.

A

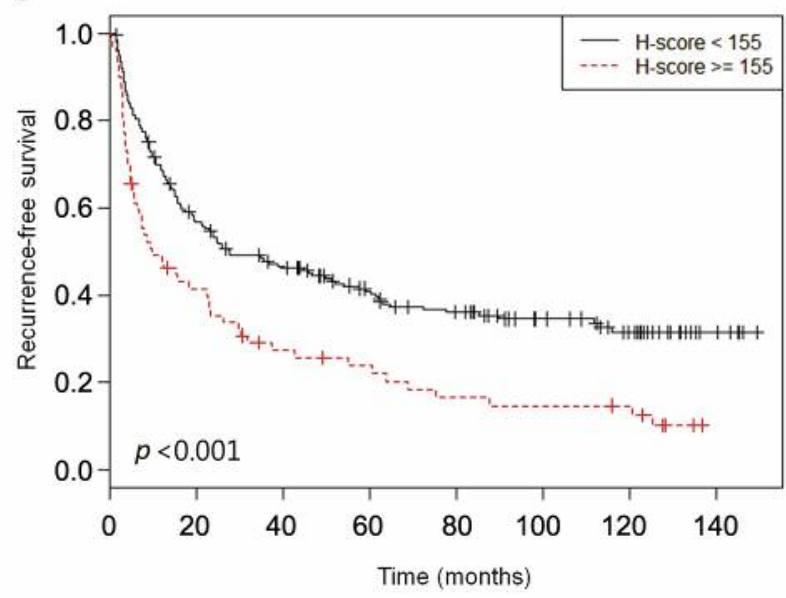

B

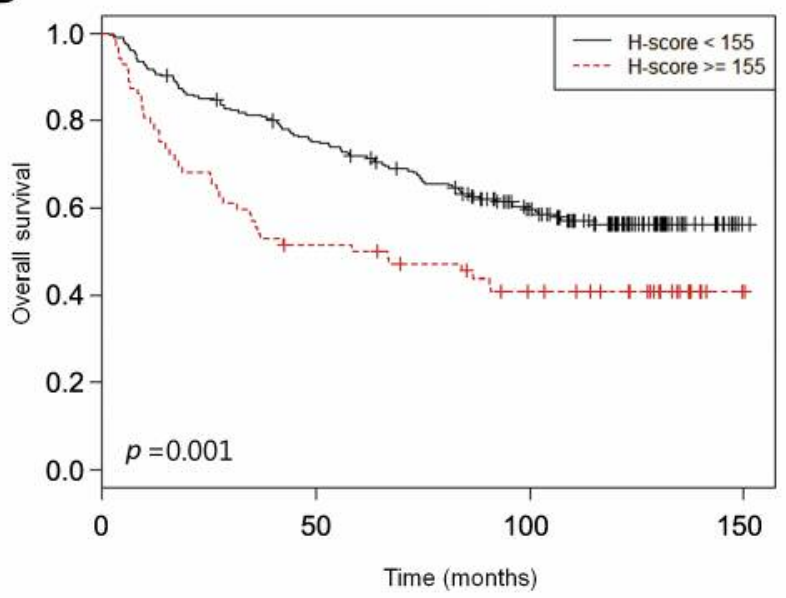

Figure 2. Kaplan-Meier survival curves for apelin receptor expression (high expression: $H$-score $\geq 155$; low expression: $H$-score $<155$ ) in 288 patients with hepatocellular carcinoma.

software, the optimal cut-off value with the most significant prognostic effect was 155 . Seventy-two cases (25\%) were considered as high expression. Normal hepatocytes, including control blocks and peritumoral liver, variably expressed negative to focal weak staining intensity.
The relationship between high APJR expression and clinicopathologic findings is shown in Table I. High APJR expression was significantly associated with younger age $(\leq 55$, $p=0.033)$, higher Edmondson grade $(p<0.001)$, advanced AJCC T-stage $(p<0.001)$, high AFP level $(p=0.023)$, microvascular 
Table I. Clinicopathologic features and correlation with apelin receptor IHC expression in 288 hepatocellular carcinomas.

\begin{tabular}{|c|c|c|c|c|c|}
\hline & Variable & $\mathrm{n}$ & Low apelin expression, $\mathrm{n}(\%)$ & High apelin expression, $\mathrm{n}(\%)$ & $p$-Value \\
\hline \multirow[t]{2}{*}{ Age } & $\leq 55$ years & 167 & $117(54.2 \%)$ & $50(69.4 \%)$ & $\mathbf{0 . 0 3 3}$ \\
\hline & $>55$ years & 121 & $99(45.8 \%)$ & $22(30.6 \%)$ & \\
\hline \multirow[t]{2}{*}{ Gender } & Female & 51 & $37(17.1 \%)$ & $14(19.4 \%)$ & 0.789 \\
\hline & Male & 237 & $179(82.9 \%)$ & $58(80.6 \%)$ & \\
\hline \multirow[t]{2}{*}{ Tumor size } & $\leq 5.0 \mathrm{~cm}$ & 192 & $151(69.9 \%)$ & $41(56.9 \%)$ & 0.061 \\
\hline & $>5.0 \mathrm{~cm}$ & 96 & $65(30.1 \%)$ & $31(43.1 \%)$ & \\
\hline \multirow[t]{3}{*}{ Edmondson grade } & I & 31 & $28(13.0 \%)$ & $3(4.2 \%)$ & $<0.001$ \\
\hline & II & 233 & $179(82.9 \%)$ & $54(75.0 \%)$ & \\
\hline & III & 24 & $9(4.2 \%)$ & $15(20.8 \%)$ & \\
\hline \multirow[t]{2}{*}{ Microvascular invasion } & $(-)$ & 132 & $113(52.3 \%)$ & $19(26.4 \%)$ & $<0.001$ \\
\hline & $(+)$ & 156 & $103(47.7 \%)$ & $53(73.6 \%)$ & \\
\hline \multirow{2}{*}{ Major portal vein invasion } & $(-)$ & 276 & $210(97.2 \%)$ & $66(91.7 \%)$ & 0.080 \\
\hline & $(+)$ & 12 & $6(2.8 \%)$ & $6(8.3 \%)$ & \\
\hline \multirow[t]{2}{*}{ Intrahepatic metastasis } & $(-)$ & 222 & $176(81.5 \%)$ & $46(63.9 \%)$ & 0.004 \\
\hline & $(+)$ & 66 & $40(18.5 \%)$ & $26(36.1 \%)$ & \\
\hline \multirow[t]{2}{*}{ Multicentric occurrence } & $(-)$ & 269 & $202(93.5 \%)$ & $67(93.1 \%)$ & 1.000 \\
\hline & $(+)$ & 19 & $14(6.5 \%)$ & $5(6.9 \%)$ & \\
\hline \multirow[t]{5}{*}{ AJCC T-stage } & 1 & 124 & $107(49.5 \%)$ & $17(23.6 \%)$ & $<0.001$ \\
\hline & 2 & 115 & $80(37.0 \%)$ & $35(48.6 \%)$ & \\
\hline & $3 \mathrm{a}$ & 32 & $18(8.3 \%)$ & $14(19.4 \%)$ & \\
\hline & $3 b$ & 11 & $5(2.3 \%)$ & $6(8.3 \%)$ & \\
\hline & 4 & 6 & $6(2.8 \%)$ & 0 & \\
\hline \multirow[t]{3}{*}{ BCLC stage } & $0-\mathrm{A}$ & 167 & $132(61.1 \%)$ & $35(48.6 \%)$ & 0.092 \\
\hline & $\mathrm{B}$ & 107 & $76(35.2 \%)$ & $31(43.1 \%)$ & \\
\hline & $\mathrm{C}$ & 14 & $8(3.7 \%)$ & $6(8.3 \%)$ & \\
\hline \multirow[t]{2}{*}{ Albumin level } & $>3.5 \mathrm{~g} / \mathrm{dl}$ & 258 & $195(90.3 \%)$ & $63(87.5 \%)$ & 0.656 \\
\hline & $\leq 3.5 \mathrm{~g} / \mathrm{dl}$ & 30 & $21(9.7 \%)$ & $9(12.5 \%)$ & \\
\hline \multirow[t]{2}{*}{ AFP level ${ }^{\mathrm{a}}$} & $\leq 200 \mathrm{ng} / \mathrm{ml}$ & 175 & $140(67.0 \%)$ & $35(50.7 \%)$ & 0.023 \\
\hline & $>200$ & 103 & $69(33.0 \%)$ & $34(49.3 \%)$ & \\
\hline \multirow[t]{2}{*}{ Etiology } & Non-viral & 49 & $37(17.1 \%)$ & $12(16.7 \%)$ & 1.000 \\
\hline & Viral (HBV or HCV) & 239 & $179(82.9 \%)$ & $60(83.3 \%)$ & \\
\hline \multirow[t]{2}{*}{ Liver cirrhosis } & $(-)$ & 143 & $99(45.8 \%)$ & $44(61.1 \%)$ & 0.035 \\
\hline & $(+)$ & 145 & $117(54.2 \%)$ & $28(38.9 \%)$ & \\
\hline \multirow[t]{2}{*}{ Early recurrence ( $\leq 2$ years) } & $(-)$ & 146 & $118(54.6 \%)$ & $28(38.9 \%)$ & 0.029 \\
\hline & $(+)$ & 142 & $98(45.4 \%)$ & $44(61.1 \%)$ & \\
\hline \multirow[t]{2}{*}{ Late recurrence (>2years) } & $(-)^{\mathrm{b}}$ & 96 & $82(69.5 \%)$ & $14(50.0 \%)$ & 0.083 \\
\hline & $(+)$ & 50 & $36(30.5 \%)$ & $14(50.0 \%)$ & \\
\hline
\end{tabular}

AJCC, American Joint Committee on Cancer 7th edition; BCLC, Barcelona Clinic Liver Cancer; AFP, $\alpha$-fetoprotein; HBV, hepatitis B virus; HCV,

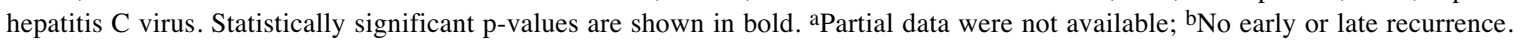

invasion $(p<0.001)$, intrahepatic metastasis $(p=0.004)$, and early recurrence $(p=0.029)$. Absence of liver cirrhosis is also significantly associated with high APJR expression $(p=0.035)$.

The RFS and OS rates of the 288 patients with HCC were $60.1 \%$ and $88.5 \%$ at 1 year, $45.1 \%$ and $80.2 \%$ at 2 years, $38.5 \%$ and $74.0 \%$ at 3 years, $28.5 \%$ and $64.2 \%$ at 5 years and $15.6 \%$ and $36.5 \%$ at 9 years, respectively. Both the RFS and OS of patients with high APJR expression were significantly shorter than in patients with low APJR expression ( $p<0.001$ and $p=0.001$, respectively) (Figure $2 \mathrm{~A}$ and $2 \mathrm{~B}$ ). The median RFS of patients with high and low APJR expression was 9.8 and 27.5 months, respectively.

On univariate analysis for prediction of RFS, larger size $(>5.0 \mathrm{~cm})$, Edmondson grade III, presence of microvascular invasion, major portal invasion, intrahepatic metastasis, higher AJCC T-stage and BCLC stage, hypoalbuminemia, higher AFP level, HBV or HCV infection, and high APJR expression showed unfavorable effects (Table II). In multivariate analysis, high APJR expression was an independent predictor of shorter RFS [Hazard Ratio $(\mathrm{HR})=1.486,95 \%$ confidence interval $(\mathrm{CI})=1.075-2.053 ; p=0.016)$, in addition to well-known prognostic factors such as intrahepatic metastasis and hepatitis virus infection (Table II).

\section{Discussion}

Apelin, a peptide encoded by the APLN gene, is an endogenous ligand for the seven-transmembrane G-protein- 
Table II. Cox proportional hazard models for prediction of recurrence free survival in 288 hepatocellular carcinoma patients.

\begin{tabular}{|c|c|c|c|c|}
\hline \multirow[t]{2}{*}{ Variable } & \multicolumn{2}{|c|}{ Univariate model } & \multicolumn{2}{|c|}{ Multivariate model } \\
\hline & HR $(95 \% \mathrm{CI})$ & $p$-Value & $\mathrm{HR}(95 \% \mathrm{CI})$ & $p$-Value \\
\hline Age, year $(\leq 55$ vs. $>55)$ & $0.957(0.716-1.278)$ & 0.765 & & \\
\hline Gender (Male $v s$. Female) & $0.974(0.678-1.400)$ & 0.887 & & \\
\hline Tumor size, $\mathrm{cm}(\leq 5.0$ vs. $>5.0)$ & $1.843(1.377-2.465)$ & $<0.001$ & $1.129(0.784-1.625)$ & 0.515 \\
\hline Edmondson grade (I+II vs. III) & $2.199(1.395-3.468)$ & $<0.001$ & $1.111(0.658-1.877)$ & 0.693 \\
\hline Microvascular invasion (No vs. Yes) & $2.255(1.681-3.023)$ & $<0.001$ & $1.200(0.826-1.745)$ & 0.339 \\
\hline Major portal vein invasion (No vs. Yes) & $6.533(3.573-11.95)$ & $<0.001$ & $1.899(0.988-3.652)$ & 0.055 \\
\hline Intrahepatic metastasis (No vs. Yes) & $5.588(4.033-7.743)$ & $<0.001$ & $4.242(2.948-6.104)$ & $<0.001$ \\
\hline Multicentric occurrence (No vs. Yes) & $1.343(0.747-2.414)$ & 0.325 & & \\
\hline AJCC T-stage $(1 v s .2+3+4)$ & $2.298(1.707-3.093)$ & $<0.001$ & & \\
\hline BCLC stage $(\mathrm{A} v s . \mathrm{B}+\mathrm{C})$ & $2.216(1.666-2.947)$ & $<0.001$ & & \\
\hline Albumin level, g/dl (>3.5 vs. $\leq 3.5)$ & $1.913(1.245-2.94)$ & 0.003 & $1.382(0.863-2.214)$ & 0.178 \\
\hline AFP level, ng/mla ( $\leq 200 v s .>200)$ & $1.700(1.271-2.273)$ & $<0.001$ & $1.336(0.986-1.810)$ & 0.061 \\
\hline Etiology (Nonviral vs. Viral) & $2.479(1.309-4.694)$ & 0.005 & $1.756(1.082-2.848)$ & 0.023 \\
\hline Liver cirrhosis (No vs. Yes) & $1.319(0.992-1.752)$ & 0.057 & $1.233(0.910-1.669)$ & 0.176 \\
\hline Apelin expression (Low vs. High) & $1.807(1.326-2.461)$ & $<0.001$ & $1.486(1.075-2.053)$ & 0.016 \\
\hline
\end{tabular}

AJCC, American Joint Committee on Cancer; BCLC, Barcelona Clinic Liver Cancer; AFP, $\alpha$-fetoprotein; HR, hazard ratio; CI, confidence interval. Statistically significant $p$-values are shown in bold. aPartial data were not available.

coupled APJR (26). Since it was first introduced from bovine stomach extracts in 1998, wide expression of apelin and APJR in many human organs has been identified (27), supporting the multitudinous functions of apelin and APJR. A variety of physiologic functions has been described, such as blood pressure control, cardiac contractility, and fluid and glucose homeostasis (8-10). Above all, angiogenesis is one of the most impressive functions of apelin and APJR. Apelin and APJR expression is essential for embryonic vascular development and has been identified in adult vessels $(11,12)$.

Hypoxia plays an important role in angiogenesis (28). It upregulates the expression of apelin derived from adipose tissue, and apelin enhances the migration and proliferation of endothelial cells (29). Angiogenesis is essential for growth and metastasis of solid tumors; thus, it is closely related to clinical outcome (30). Recent studies showed that apelin induced vascular maturation and tumor growth. Apelin upregulation is also associated with poor clinical outcome in several cancer types (13-15). In non-small cell lung cancer, apelin mRNA level was increased and high apelin protein level was related to increased microvascular density and poor OS (13). Colon cancer, brain tumor, and HCC showed elevated expression of apelin and/or APJR and accompanying microvascular proliferation $(14,15,31)$. Stimulation of tumor-induced angiogenesis raises the possibility of lymphovascular invasion and metastasis (32). A recent study on lymphangiogenesis revealed an association of apelin overexpression and lymph node metastasis (33).

HCC shows typical vascular abnormalities compared to non-tumorous liver. Unlike the dual arterial and portal blood flow supply of non-tumor liver, HCC only receives arterial supply. Arteriogenesis of HCC originates from pre-existing arteries with proliferation of smooth muscle cells. A recent study by Muto et al. showed APJR expression in arterial smooth muscle cells of HCC, and induction of smooth muscle cell proliferation by apelin treatment (18). These results suggest the impact of apelin and APJR system on typical arteriogenesis in HCC.

In our study, high expression of APJR in HCC was significantly associated with microvascular invasion and intrahepatic metastasis. High expression of APJR in HCC was also an independent factor for shorter RFS. This finding supports the evidence that apelin is involved in arteriogenesis and vascular invasion in HCC. Apelin and APJR may play important roles in early recurrence. Intrahepatic metastasis is a major contributor to early recurrence, which is the most important factor in predicting clinical outcome with HCC. APJR expression can be considered an excellent predictive marker of RFS.

Due to its function in energy metabolism and insulin sensitivity, apelin has recently become a promising target for treating a broad range of diseases, including type 2 diabetes, obesity, dyslipidemia, cardiovascular disease, kidney disease, and liver disease $(16,17,34,35)$. On the basis of angiogenesis in tumor progression, the development of a potential targeting therapy has been suggested (13). In colon adenocarcinoma cell line, APJR antagonist significantly reduced the proliferation rate of tumor cells (14). Selective competitive antagonists of APJ receptor suppressed glioblastoma growth in vivo and prolonged survival of 
intracranially xenografted mice (15). APJR antagonist also inhibited in vivo tumor growth in cholangiocarcinoma and HCC $(18,36)$. Based on the function of apelin and APJR in HCC progression, targeted antagonist may reduce tumor growth and angiogenesis while lengthening RFS.

\section{Conclusion}

High expression of APJR in HCC tissue specimens was demonstrated to be an excellent marker related to microvascular invasion, intrahepatic metastasis, and shorter RFS. Moreover, APJR expression was suggested as an independent predictor of RFS. To the best of our knowledge this is the first study to assess APJR expression on clinical outcomes of patients with HCC. Emerging target agents against apelin or APJR may be applicable in patients with HCC with high APJR expression.

\section{Authors' Contributions}

Conception and design: TL, SYH; Acquisition of data: CKP; Analysis and interpretation of data: TL, CKP, SYH; Drafting the article: TL, SYH; Revising and final approval of the article to be published: TL, SYH; All authors read and approved the final manuscript.

\section{Acknowledgements}

This study was funded by Samsung Medical Center intramural grant (\#SMO1161731).

\section{References}

1 Global Burden of Disease Liver Cancer C, Akinyemiju T, Abera S, Ahmed M, Alam N, Alemayohu MA, Allen C, Al-Raddadi R, Alvis-Guzman N, Amoako Y, Artaman A, Ayele TA, Barac A, Bensenor I, Berhane A, Bhutta Z, Castillo-Rivas J, Chitheer A, Choi JY, Cowie B, Dandona L, Dandona R, Dey S, Dicker D, Phuc H, Ekwueme DU, Zaki MS, Fischer F, Furst T, Hancock J, Hay SI, Hotez P, Jee SH, Kasaeian A, Khader Y, Khang YH, Kumar A, Kutz M, Larson H, Lopez A, Lunevicius R, Malekzadeh R, McAlinden C, Meier T, Mendoza W, Mokdad A, Moradi-Lakeh M, Nagel G, Nguyen Q, Nguyen G, Ogbo F, Patton G, Pereira DM, Pourmalek F, Qorbani M, Radfar A, Roshandel G, Salomon JA, Sanabria J, Sartorius B, Satpathy M, Sawhney M, Sepanlou S, Shackelford K, Shore H, Sun J, Mengistu DT, Topor-Madry R, Tran B, Ukwaja KN, Vlassov V, Vollset SE, Vos T, Wakayo T, Weiderpass E, Werdecker A, Yonemoto N, Younis M, Yu C, Zaidi Z, Zhu L, Murray CJL, Naghavi $M$ and Fitzmaurice C: The Burden of primary liver cancer and underlying etiologies from 1990 to 2015 at the global, regional, and national level: Results From the Global Burden of Disease Study 2015. JAMA Oncol 3: 1683-1691, 2017. PMID: 28983565. DOI: 10.1001/jamaoncol.2017.3055

2 Sherman M: Recurrence of hepatocellular carcinoma. N Engl J Med 359: 2045-2047, 2008. PMID: 18923166. DOI: 10.1056/NEJMe0807581
3 Portolani N, Coniglio A, Ghidoni S, Giovanelli M, Benetti A, Tiberio GA and Giulini SM: Early and late recurrence after liver resection for hepatocellular carcinoma: prognostic and therapeutic implications. Ann Surg 243: 229-235, 2006. PMID: 16432356. DOI: 10.1097/01.sla.0000197706.21803.a1

4 Villanueva $A$ and Llovet JM: Targeted therapies for hepatocellular carcinoma. Gastroenterology 140: 1410-1426, 2011. PMID: 21406195. DOI: 10.1053/j.gastro.2011.03.006

5 Bruix J, Qin S, Merle P, Granito A, Huang YH, Bodoky G, Pracht M, Yokosuka O, Rosmorduc O, Breder V, Gerolami R, Masi G, Ross PJ, Song T, Bronowicki JP, Ollivier-Hourmand I, Kudo M, Cheng AL, Llovet JM, Finn RS, LeBerre MA, Baumhauer A, Meinhardt G, Han G and Investigators R: Regorafenib for patients with hepatocellular carcinoma who progressed on sorafenib treatment (RESORCE): a randomised, double-blind, placebo-controlled, phase 3 trial. Lancet 389: 5666, 2017. PMID: 27932229. DOI: $10.1016 /$ S0140-6736(16) 32453-9

6 Kudo M, Finn RS, Qin S, Han KH, Ikeda K, Piscaglia F, Baron A, Park JW, Han G, Jassem J, Blanc JF, Vogel A, Komov D, Evans TRJ, Lopez C, Dutcus C, Guo M, Saito K, Kraljevic S, Tamai T, Ren M and Cheng AL: Lenvatinib versus sorafenib in first-line treatment of patients with unresectable hepatocellular carcinoma: a randomised phase 3 non-inferiority trial. Lancet 391: 1163-1173, 2018. PMID: 29433850. DOI: 10.1016/S01406736(18)30207-1

7 Qin LX and Tang ZY: Recent progress in predictive biomarkers for metastatic recurrence of human hepatocellular carcinoma: a review of the literature. J Cancer Res Clin Oncol 130: 497-513, 2004. PMID: 15205947. DOI: 10.1007/s00432-004-0572-9

$8 \mathrm{Wu}$ D, He L and Chen L: Apelin/APJ system: a promising therapy target for hypertension. Mol Biol Rep 41: 6691-6703, 2014. PMID: 24990699. DOI: 10.1007/s11033-014-3552-4

9 Bertrand C, Valet P and Castan-Laurell I: Apelin and energy metabolism. Front Physiol 6: 115, 2015. PMID: 25914650. DOI: 10.3389/fphys.2015.00115

10 Lv SY, Yang YJ and Chen Q: Regulation of feeding behavior, gastrointestinal function and fluid homeostasis by apelin. Peptides 44: 87-92, 2013. PMID: 23557907. DOI: 10.1016/ j.peptides.2013.03.024

11 Devic E, Rizzoti K, Bodin S, Knibiehler B and Audigier Y: Amino acid sequence and embryonic expression of msr/apj, the mouse homolog of Xenopus X-msr and human APJ. Mech Dev 84: 199-203, 1999. PMID: 10473142. DOI: 10.1016/S09254773(99)00081-7

12 Kleinz MJ and Davenport AP: Immunocytochemical localization of the endogenous vasoactive peptide apelin to human vascular and endocardial endothelial cells. Regul Pept 118: 119-125, 2004. PMID: 15003827. DOI: 10.1016/j.regpep.2003.11.002

13 Berta J, Kenessey I, Dobos J, Tovari J, Klepetko W, Jan Ankersmit H, Hegedus B, Renyi-Vamos F, Varga J, Lorincz Z, Paku S, Ostoros G, Rozsas A, Timar J and Dome B: Apelin expression in human non-small cell lung cancer: role in angiogenesis and prognosis. J Thorac Oncol 5: 1120-1129, 2010. PMID: 20581707. DOI: 10.1097/JTO.0b013e3181e2c1ff

14 Picault FX, Chaves-Almagro C, Projetti F, Prats H, Masri B and Audigier Y: Tumour co-expression of apelin and its receptor is the basis of an autocrine loop involved in the growth of colon adenocarcinomas. Eur J Cancer 50: 663-674, 2014. PMID: 24316062. DOI: 10.1016/j.ejca.2013.11.017 
15 Harford-Wright E, Andre-Gregoire G, Jacobs KA, Treps L, Le Gonidec S, Leclair HM, Gonzalez-Diest S, Roux Q, Guillonneau F, Loussouarn D, Oliver L, Vallette FM, Foufelle F, Valet P, Davenport AP, Glen RC, Bidere N and Gavard J: Pharmacological targeting of apelin impairs glioblastoma growth. Brain 140: 29392954, 2017. PMID: 29053791. DOI: 10.1093/brain/awx253

16 Castan-Laurell I, Dray C, Knauf C, Kunduzova O and Valet P: Apelin, a promising target for type 2 diabetes treatment? Trends Endocrinol Metab 23: 234-241, 2012. PMID: 22445464. DOI: 10.1016/j.tem.2012.02.005

$17 \mathrm{Lv}$ D, Li H and Chen L: Apelin and APJ, a novel critical factor and therapeutic target for atherosclerosis. Acta Biochim Biophys Sin (Shanghai) 45: 527-533, 2013. PMID: 23588025. DOI: 10.1093/abbs/gmt040

18 Muto J, Shirabe K, Yoshizumi T, Ikegami T, Aishima S, Ishigami K, Yonemitsu Y, Ikeda T, Soejima Y and Maehara Y: The apelinAPJ system induces tumor arteriogenesis in hepatocellular carcinoma. Anticancer Res 34: 5313-5320, 2014. PMID: 25275024.

19 Edmondson HA and Steiner PE: Primary carcinoma of the liver: a study of 100 cases among 48,900 necropsies. Cancer 7: 462503, 1954. PMID: 13160935.

20 Liver Cancer Study Group of Japan: The general rules for the clinical and pathological study of primary liver cancer. 2 nd ed. Tokyo, Kanahara, 2003.

21 Edge SB and Compton CC: AJCC cancer staging manual. 7th ed. Chicago, IL, Springer, 2010.

22 Llovet JM, Bru C and Bruix J: Prognosis of hepatocellular carcinoma: the BCLC staging classification. Semin Liver Dis 19: 329-338, 1999. PMID: 10518312. DOI: 10.1055/s-20071007122

23 Shimada M, Hamatsu T, Yamashita Y, Rikimaru T, Taguchi K, Utsunomiya T, Shirabe K and Sugimachi K: Characteristics of multicentric hepatocellular carcinomas: comparison with intrahepatic metastasis. World J Surg 25: 991-995, 2001. PMID: 11571981. DOI: 10.1007/s00268-001-0068-6

24 Imamura H, Matsuyama Y, Tanaka E, Ohkubo T, Hasegawa K, Miyagawa S, Sugawara Y, Minagawa M, Takayama T, Kawasaki $\mathrm{S}$ and Makuuchi M: Risk factors contributing to early and late phase intrahepatic recurrence of hepatocellular carcinoma after hepatectomy. J Hepatol 38: 200-207, 2003. PMID: 12547409. DOI: $10.1016 / \mathrm{S} 0168-8278(02) 00360-4$

25 Camp RL, Dolled-Filhart M and Rimm DL: X-tile: a new bioinformatics tool for biomarker assessment and outcome-based cut-point optimization. Clin Cancer Res 10: 7252-7259, 2004 PMID: 15534099. DOI: 10.1158/1078-0432.CCR-04-0713

26 Tatemoto K, Hosoya M, Habata Y, Fujii R, Kakegawa T, Zou MX, Kawamata Y, Fukusumi S, Hinuma S, Kitada C, Kurokawa $\mathrm{T}$, Onda $\mathrm{H}$ and Fujino $\mathrm{M}$ : Isolation and characterization of a novel endogenous peptide ligand for the human APJ receptor. Biochem Biophys Res Commun 251: 471-476, 1998. PMID: 9792798. DOI: 10.1006/bbrc.1998.9489
27 Pitkin SL, Maguire JJ, Bonner TI and Davenport AP: International Union of Basic and Clinical Pharmacology. LXXIV. Apelin receptor nomenclature, distribution, pharmacology, and function. Pharmacol Rev 62: 331-342, 2010. PMID: 20605969. DOI: 10.1124/pr.110.002949

28 Hickey MM and Simon MC: Regulation of angiogenesis by hypoxia and hypoxia-inducible factors. Curr Top Dev Biol 76: 217-257, 2006. PMID: 17118268. DOI: 10.1016/S0070-2153(06) $76007-0$

29 Kunduzova O, Alet N, Delesque-Touchard N, Millet L, CastanLaurell I, Muller C, Dray C, Schaeffer P, Herault JP, Savi P, Bono F and Valet P: Apelin/APJ signaling system: a potential link between adipose tissue and endothelial angiogenic processes. FASEB J 22: 4146-4153, 2008. PMID: 18708591. DOI: $10.1096 / f j .07-104018$

30 Pang RW and Poon RT: Clinical implications of angiogenesis in cancers. Vasc Health Risk Manag 2: 97-108, 2006. PMID: 17319453.

31 Liu Q, Hu T, He L, Huang X, Tian X, Zhang H, He L, Pu W, Zhang L, Sun H, Fang J, Yu Y, Duan S, Hu C, Hui L, Zhang H, Quertermous T, Xu Q, Red-Horse K, Wythe JD and Zhou B: Genetic targeting of sprouting angiogenesis using Apln-CreER. Nat Commun 6: 6020, 2015. PMID: 25597280. DOI: 10.1038/ncomms 7020

32 Maehara Y, Kabashima A, Koga T, Tokunaga E, Takeuchi H, Kakeji Y and Sugimachi K: Vascular invasion and potential for tumor angiogenesis and metastasis in gastric carcinoma. Surgery 128: 408-416, 2000. PMID: 10965312. DOI: 10.1067/ msy.2000.107265

33 Berta J, Hoda MA, Laszlo V, Rozsas A, Garay T, Torok S, Grusch M, Berger W, Paku S, Renyi-Vamos F, Masri B, Tovari J, Groger M, Klepetko W, Hegedus B and Dome B: Apelin promotes lymphangiogenesis and lymph node metastasis. Oncotarget 5: 4426-4437, 2014. PMID: 24962866. DOI: 10.18632/oncotarget.2032

34 Huang Z, Wu L and Chen L: Apelin/APJ system: A novel potential therapy target for kidney disease. J Cell Physiol 233: 3892-3900, 2018. PMID: 28796300. DOI: 10.1002/jcp.26144

35 Lv SY, Cui B, Chen WD and Wang YD: Apelin/APJ system: A key therapeutic target for liver disease. Oncotarget 8 : 112145112151, 2017. PMID: 29340118. DOI: 10.18632/oncotarget. 22841

36 Hall C, Ehrlich L, Venter J, O'Brien A, White T, Zhou T, Dang T, Meng F, Invernizzi P, Bernuzzi F, Alpini G, Lairmore TC and Glaser S: Inhibition of the apelin/apelin receptor axis decreases cholangiocarcinoma growth. Cancer Lett 386: 179-188, 2017. PMID: 27894959. DOI: 10.1016/j.canlet.2016.11.025

Received April 3, 2019

Revised May 21, 2019

Accepted May 22, 2019 